\title{
Effects of Mother's Smoking on their Infants' Body Composition as Determined by Total Body Potassium
}

\author{
DONALD W. SPADY, MAUREEN A. ATRENS, AND WALDEMAR A. SZYMANSKI
}

Department of Pediatrics, Faculty of Medicine, University of Alberta, Edmonton, Alberta, Canada

\begin{abstract}
It has been suggested that the lower birth weight of newborn infants of mothers who smoke is due mainly to a deficit of lean body mass (LBM). We tested this hypothesis by measuring total body potassium, thus deriving the LBM and fat mass, of newborn infants of mothers who smoked (I-SM; $\boldsymbol{n}=32$ ) or did not smoke (INSM; $n=46)$. Mothers who smoked were significantly younger than nonsmoking ones (25.4 and $28.9 \mathrm{yr}$, respectively) and with less years of education, but were similar in other parameters examined. The 78 infants, all singleton, were studied within 1 to 3 days of birth. The I-SM had significantly reduced birth weight, length, and head circumference but there was no difference in skinfold thickness. We measured total body potassium with a whole-body counter specially made for use with infants. Mean absolute total body potassium was significantly greater in the INSM, but the concentration in relation to weight was not different. Assuming $1 \mathrm{~kg}$ LBM to contain $52.1 \mathrm{mmol}$ potassium, the mean LBM was $3028 \mathrm{~g}$ in the I-NSM and 2739 in the I-SM; mean fat mass was similar in both groups. Multiple regression analysis revealed an independent negative effect of mother's smoking on birth weight and LBM. This unequal reduction in LBM indicates a complex effect of smoking, probably mediated by alterations in protein synthesis and adipocyte metabolism. It may relate to the higher morbidity rates in infants of mothers who smoke. (Pediatr Res 20: 716-719, 1986)
\end{abstract}

\section{Abbreviations}

I-NSM, infants of non smoking mothers

I-SM, infants of mothers who smoked

LBM, lean body mass

TBK, total body potassium

The adverse effects on newborn infants of their mothers' smoking during pregnancy include decreased birth weight, length, and head circumference $(1,2)$. Harrison et al. (3), using measures of skinfold thickness and arm muscle circumference, postulated recently that the reduction in birth weight of infants whose mothers smoke is due primarily to reduction in the LBM and that the deposition of subcutaneous fat is little affected. This concurs with others' findings $(4,5)$. However, in all of these studies the conclusions were based on indirect measures of body

Received January 3, 1986; accepted March 13, 1986.

Address for correspondence and reprints Donald W. Spady, M.D., M.Sc. F.R.C.P.(C), Department of Pediatrics, 2C300 Mackenzie Health Sciences Centre, University of Alberta, Edmonton, Alberta, Canada T6G 3R7.

Support for W. A. S. and M. A. A. was provided by the Alberta Heritage Foundation for Medical Research. composition; therefore it was not possible to provide more than qualitative statements about the kinds of tissues affected.

In order to apply more quantitative methods, in the present study we measured TBK in infants of smoking and nonsmoking mothers. As $\mathrm{K}$ is found only in the lean tissues of the body, the measurement of TBK permits quantitative assessment of lean and fat tissue. Our objectives were (a) to verify the effect of mothers' smoking on their infants' birth weight; (b) to determine whether the commonly observed difference in birth weight of infants of mothers who smoke is due largely to reduced lean body mass, as has been postulated; (c) to use the TBK measurements to estimate the lean body mass and fat mass of infants of mothers who smoke (I-SM) and of mothers who do not smoke (I-NSM); and (d) to attempt quantification of the composition of any tissue deficit in the infants of smoking mothers.

\section{SUBJECTS AND METHODS}

We studied singleton, full-term, healthy neonates who were born in the University of Alberta Hospital during June and July 1985. Subjects were recruited by asking the mothers of newborn infants whether they were willing to participate in a study of infant growth. The Hospital's ethics committee approved the research in detail, and we obtained the mothers' informed consent for all procedures. The observer was not blinded with respect to the infants' groups, and the selection of subjects may have been biased by self-selection on the part of the participating parents.

Gestation and birth weight were recorded from the infant's birth record. In addition to details of the pregnancy (mother's age, height, reported prepregnant weight, reported weight gain in pregnancy, parity, gravidity, length of time between pregnancies, type of delivery, health status during pregnancy), data were obtained by interview describing the mother's level of education and the amount of alcohol and drug use. Information about her smoking habits before and during pregnancy and those of other members of the household was also obtained. Mothers were classified as smokers if they smoked regularly any number of cigarettes before and during the pregnancy and were classified as nonsmokers if neither they nor other members of the household smoked. The frequency and amount of smoking also was recorded, but the subjects were too few for division of the smoker group into subsets. As the subjects were recruited after birth, no retrospective information about the mother's diet during pregnancy was obtained; we believed the validity of such data would be dubious.

At the time of measurement of TBK, the infant's study weight was measured on a Scaletronix pediatric scale, length was determined with a neonatometer, and head circumference was measured with a disposable heavy paper tape. Skinfold measurements were made at triceps, biceps, subscapular, and suprailiac sites using Lange skinfold calipers applied with pressure maintained until the reading became stable (about 20 to $30 \mathrm{~s}$ ). 
TBK was measured with a whole-body counter specially designed and constructed for use with infants $(6,7)$; we have used this instrument to measure TBK in more than 150 infants ranging in weight from 900 to $4500 \mathrm{~g}$. The instrument consists of a single $\mathrm{NaI}(\mathrm{Tl})$ crystal, $10 \times 10 \times 45 \mathrm{~cm}$, positioned lengthways and shielded from environmental background radiation by a lead lining $10 \mathrm{~cm}$ thick. Validation of the machine by comparison of whole-body counter estimates of TBK in stillborn pigs with subsequent carcass analysis has yielded agreement within $3 \%$. Analysis of counting statistics showed a theoretical error of $8.3 \%$ in single measurements from infants of the average size studied, and reproducibility of $4.7 \%$ of measurements on sequential days of infants weighing more than $2500 \mathrm{~g}$.

The instrument was calibrated with Plexiglass phantoms approximating the size and shape of an infant and containing varying amounts of potassium. For measurement of TBK, the infant was placed in a chamber above and in full view of the crystal. The infant was under constant observation and body heat was maintained by using a heat lamp, $1 \mathrm{~m}$ distant, directed at the infant. The data were acquired by a 1024-channel analyzer, through a 100-channel "window" with the $1.46 \mathrm{MeV}{ }^{40} \mathrm{~K}$ peak in the center as the ${ }^{40} \mathrm{~K}$ signal. Counts were acquired for $2000 \mathrm{~s}$ and the data transmitted to a microcomputer for storage and analysis.

LBM was estimated from the TBK measurement, with the assumption that $1 \mathrm{~kg}$ of LBM contains $52.1 \mathrm{mEq}$ of potassium (8). (This is not a fixed constant; figures ranging from 47 to 58 mEq TBK per $1 \mathrm{~kg}$ LBM give the same qualitative results.) Fat mass was assumed to be the difference between LBM and study weight.

The data were analyzed using SPSS/PC+. Descriptive statistics of each parameter were calculated, and intergroup differences determined with a two-tailed $t$ test. Correlation coefficients were calculated between birth weight and all variables collected which had the potential to affect birth weight or LBM. Variables correlating significantly with birth weight or LBM $(p<0.05)$ and which theoretically could influence birth weight were then used in a multiple regression procedure to determine the degree to which they accounted for birth weight or LBM. Since, in the present instance, we were not interested simply in an equation to predict birth weight from a set of variables but instead wanted some estimate of the degree to which smoking independently affected birth weight or LBM, other significant variables were entered into the equation prior to entering smoking. Variables were dropped from the equation if they failed to increase the $\mathrm{R}^{2}$ value by more than $1 \%$.

\section{RESULTS}

Data were obtained on 78 mother-infant pairs; 46 mothers had never smoked and 32 mothers smoked regularly before and during the pregnancy. Of the mothers who smoked, $47 \%$ smoked more than half a packet a day; during the pregnancy, $56 \%$ reduced the amount they smoked but only $10 \%$ reduced this smoking by more than half. The mothers who smoked were significantly younger than nonsmoking mothers, averaging 25.4 and 28.9 yr, respectively (Table 1), and were less educated, with 28.1 and $74.4 \%$, respectively, having over $12 \mathrm{yr}$ of education (not shown in Table 1). There were no significant differences in maternal height, reported prepregnancy weight, weight gain during the pregnancy, parity, or gravidity. The reported frequency or amount of ethanol consumption was not significantly different between groups and nontherapeutic drug use was denied by all subjects.

Between the two groups of infants, there were statistically significant differences in mean birth weight, study weight, TBK, head circumference, and length, the I-SM being less in each instance, but mean skinfold thickness and $\mathrm{TBK} / \mathrm{kg}$ were not significantly different (Table 2). The mean difference in birth weight was $358 \mathrm{~g}$ and in study weight was $295 \mathrm{~g}$, the I-NSM losing, on the average, almost twice as much as the I-SM.

The calculated lean body mass was significantly less in the ISM than in the I-NSM, but the fat mass was virtually identical in the two groups (Table 3). The difference in mean study weights was $295 \mathrm{~g}$, and whereas the average LBM was $289 \mathrm{~g}$ greater in the I-NSM, the difference in fat was only $6 \mathrm{~g}$.

The variables of gestation, prepregnant weight, the practice of smoking, the length of time between pregnancies (pregnancy interval), and mother's age, correlated significantly with birth weight (Table 4) and were used, together with the infant's sex (which did not correlate with birth weight but did account for over $1 \%$ of the variance in birth weight), in the regression analysis. The first four variables also correlated significantly with LBM. As could be expected, gestation correlated most strongly with birth weight; the mother's smoking correlated nearly as strongly, but negatively.

Table 2. Basic study data of the two groups of infants (mean \pm $S D)$

\begin{tabular}{lccc}
\hline & $\begin{array}{c}\text { I-NSM } \\
(n=46)\end{array}$ & $\begin{array}{c}\text { I-SM } \\
(n=32)\end{array}$ & $\begin{array}{c}\text { I-NSM vs I-SM } \\
p\end{array}$ \\
\hline Gestation (wk) & $39.6 \pm 1.5$ & $39.0 \pm 1.9$ & NS \\
Birth wt (g) & $3539 \pm 388$ & $3181 \pm 430$ & $<0.001$ \\
Length (cm) & $51.4 \pm 1.8$ & $50.0 \pm 1.8$ & $<0.001$ \\
Head circumference (cm) & $35.4 \pm 1.1$ & $34.8 \pm 1.0$ & $<0.05$ \\
Study wt (g) & $3405 \pm 373$ & $3110 \pm 393$ & $<0.01$ \\
Study age (h) & $54.7 \pm 26.6$ & $61.7 \pm 20.6$ & NS \\
Body potassium (mEq) & $157.8 \pm 19.0$ & $142.7 \pm 20.2$ & $<0.01$ \\
Body potassium (mEq/ & $46.4 \pm 3.8$ & $46.1 \pm 5.0$ & NS \\
kg) & & & \\
Skinfold measurements & & & \\
$\quad$ Biceps (mm) & $4.3 \pm 0.9$ & $4.5 \pm 0.8$ & NS \\
$\quad$ Triceps (mm) & $4.6 \pm 1.1$ & $4.6 \pm 1.0$ & NS \\
Subscapular (mm) & $4.8 \pm 1.0$ & $4.7 \pm 0.9$ & NS \\
\multicolumn{1}{l}{ Suprailiac (mm) } & $5.0 \pm 1.1$ & $5.2 \pm 1.4$ & NS \\
\hline
\end{tabular}

Table 3. Calculated body composition of I-SM and I-NSM (mean $\pm S D)$

\begin{tabular}{lccc}
\hline & $\begin{array}{c}\text { I-NSM } \\
\text { (study wt, g) }\end{array}$ & $\begin{array}{c}\text { I-SM } \\
\text { (study wt, g) }\end{array}$ & $\begin{array}{c}\text { I-NSM } v \text { I-SM } \\
\text { ( }\end{array}$ \\
\hline LBM $(\mathrm{g})$ & $3405 \pm 373$ & $3110 \pm 393$ & \\
Fat mass (g) & $3028 \pm 366$ & $2739 \pm 388$ & $<0.001$ \\
$\%$ lean tissue & $89.1 \pm 7.3$ & $88.4 \pm 9.7$ & NS \\
$\%$ fat tissue & $10.9 \pm 7.3$ & $11.6 \pm 9.7$ & NS \\
\hline
\end{tabular}

Table 1. Basic study data of the two groups of mothers (mean $\pm S D$ )

\begin{tabular}{|c|c|c|c|}
\hline & $\begin{array}{l}\text { Nonsmoking mothers } \\
\quad(n=46)\end{array}$ & $\begin{array}{c}\text { Smoking mothers } \\
(n=32)\end{array}$ & $\begin{array}{c}\text { Nonsmoking vs smoking } \\
p\end{array}$ \\
\hline Age (yr) & $28.9 \pm 4.6$ & $25.5 \pm 4.8$ & $<0.01$ \\
\hline $\mathrm{Ht}(\mathrm{cm})$ & $164.3 \pm 6.2$ & $162.4 \pm 7.0$ & NS \\
\hline Prepregnant wt $(\mathrm{kg})$ & $59.3 \pm 10.9$ & $59.7 \pm 11.6$ & NS \\
\hline Wt gain $(\mathrm{kg})$ & $14.3 \pm 4.1$ & $13.8 \pm 5.3$ & NS \\
\hline Parity & $1.8 \pm 0.8$ & $1.8 \pm 1.5$ & NS \\
\hline Gravidity & $2.1 \pm 1.1$ & $2.3 \pm 1.9$ & NS \\
\hline
\end{tabular}


Table 4. Correlation matrix of variables associated significantly with birth wt or LBM

\begin{tabular}{|c|c|c|c|c|c|c|c|c|c|c|}
\hline & LBM & Gestation & $\begin{array}{l}\text { Pregnancy } \\
\text { interval }\end{array}$ & $\begin{array}{l}\text { Mother's } \\
\text { smoking }\end{array}$ & $\begin{array}{c}\text { Prepregnant } \\
\text { wt }\end{array}$ & $\begin{array}{l}\text { Maternal } \\
\text { age }\end{array}$ & Length & $\begin{array}{c}\text { Head } \\
\text { circumference }\end{array}$ & $\begin{array}{l}\text { Skinfold } \\
\text { thickness* }\end{array}$ & $\begin{array}{c}\text { Infant's } \\
\text { sex }\end{array}$ \\
\hline Birth wt & $0.743 \dagger$ & $0.580 \dagger$ & $0.205 \ddagger$ & $-0.438 \dagger$ & $0.336 \S$ & $0.301 \S$ & $0.779 \dagger$ & $0.661 \dagger$ & $0.526 \dagger$ & 0.100 \\
\hline LBM & & $0.486 \dagger$ & 0.182 & $-0.356 \S$ & $0.212 \ddagger$ & $0.140^{\circ}$ & $0.579 \dagger$ & $0.564 \dagger$ & $0.364 \S$ & 0.036 \\
\hline Gestation & & & -0.114 & -0.189 & $0.057^{\circ}$ & -0.001 & $0.589 \dagger$ & $0.396 \dagger$ & $0.178^{\circ}$ & -0.169 \\
\hline Pregnancy interval & & & & -0.101 & $0.219 \ddagger$ & $0.471 \dagger$ & 0.034 & 0.030 & 0.184 & 0.002 \\
\hline Mother's smoking & & & & & 0.021 & $-0.339 \S$ & $-0.372 \dagger$ & $-0.285 \S$ & -0.020 & -0.034 \\
\hline Prepregnant weight & & & & & & 0.129 & $0.240 \ddagger$ & $0.273 \S$ & $0.303 \S$ & 0.061 \\
\hline Maternal age & & & & & & & 0.174 & $0.233 \ddagger$ & 0.161 & $0.259 \ddagger$ \\
\hline Infant's length & & & & & & & & $0.664 \dagger$ & $0.299 \S$ & $-0.001^{\circ}$ \\
\hline Head circumference & & & & & & & & & $0.258 \ddagger$ & $0.337 \dagger$ \\
\hline Skinfold thickness* & & & & & & & & & & -0.184 \\
\hline
\end{tabular}

* Skinfold thickness refers to the sum of the triceps, biceps, suprailiac, and subscapular skinfolds.

$\dagger p<0.001$.

$\ddagger p<0.05$.

$\S p<0.01$.

Table 5. Multiple regression analysis

\begin{tabular}{|c|c|c|c|c|c|c|c|c|}
\hline Variable & $\begin{array}{c}\text { B } \\
\text { (slope) }\end{array}$ & $\begin{array}{l}\text { SE } \\
\text { B }\end{array}$ & $\mathrm{T}$ & $\begin{array}{l}\text { Sign. } \\
\mathrm{T}\end{array}$ & $\begin{array}{c}\text { Partial } \\
\text { correlation }\end{array}$ & $\begin{array}{l}\text { Multiple } \\
\mathrm{R}\end{array}$ & $\mathrm{R}^{2}$ & $\begin{array}{c}\mathrm{R}^{2} \\
\text { change }\end{array}$ \\
\hline \multicolumn{9}{|l|}{ A. Variables accounting for birth wt } \\
\hline Gestation & 141 & 20.25 & 6.968 & 0.0000 & 0.6427 & 0.5802 & 0.3366 & 0.3366 \\
\hline Pregnancy interval & 2.75 & 1.57 & 1.745 & 0.0855 & 0.2056 & 0.6413 & 0.4113 & 0.0747 \\
\hline Mother's age & 3.11 & 8.47 & 0.367 & 0.7148 & 0.0441 & 0.6739 & 0.4541 & 0.0428 \\
\hline Prepregnant wt & 10.11 & 3.01 & 3.357 & 0.0013 & 0.3747 & 0.7157 & 0.5122 & 0.0581 \\
\hline Infant's sex $(F=0 ; M=1)$ & 143 & 69.94 & 2.044 & 0.0448 & 0.2389 & 0.7272 & 0.5288 & 0.0166 \\
\hline Mother's smoking (no $=0$; yes $=1$ ) & -269 & 73.69 & -3.645 & 0.0005 & -0.4018 & 0.7777 & 0.6049 & 0.0761 \\
\hline Constant & -2896 & 839 & -3.450 & 0.0010 & & & & \\
\hline \multicolumn{9}{|l|}{ B. Variables accounting for LBM } \\
\hline Gestation & 105 & 22.72 & 4.633 & 0.0000 & 0.4818 & 0.4864 & 0.2366 & 0.2366 \\
\hline Pregnancy interval & 2.87 & 1.61 & 1.779 & 0.0796 & 0.2065 & 0.5422 & 0.2940 & 0.0574 \\
\hline Prepregnant wt & 5.42 & 3.42 & 1.586 & 0.1172 & 0.1849 & 0.5584 & 0.3118 & 0.0178 \\
\hline $\begin{array}{l}\text { Mother's smoking }(\text { no }=0 ; \text { yes }=1) \\
\quad(\text { no }=0 ; \text { yes }=1)\end{array}$ & -204 & 76.97 & -2.660 & 0.0097 & -0.3010 & 0.6117 & 0.3742 & 0.0624 \\
\hline Constant & -1310 & 913 & -1.435 & 0.1555 & & & & \\
\hline
\end{tabular}

Multiple regression analysis, with the variables entered in the following order: (a) gestation, (b) pregnancy interval, (c) mother's age, (d) prepregnant weight, (e) infant's sex, and (f) smoking habit, was able to account for a total of $60.5 \%$ of the variance in birth weight. Smoking by the mother independently accounted for $7.6 \%$ of the variance in birth weight and had the direct effect of reducing birth weight by $269 \mathrm{~g}$. Prepregnant weight, pregnancy interval, and mother's age together accounted for $17.6 \%$, the infant's sex accounted for $1.7 \%$, and gestation accounted for $33.7 \%$ (Table 5).

Other variables, such as length or head circumference, while highly correlated with birth weight (Table 4), were not used in the regression analysis because they did not contribute to the causal analysis of factors and in fact would be affected by the same variables as affected birth weight; as seen also with birth weight, length and head circumference were strongly and negatively associated with smoking. The years of education of the mother was an antecedent variable which also correlated significantly with birth weight (not in Table 4), but, since it could not directly influence birth weight, it was not entered into the regression analysis.

Regression analysis was used also to determine the degree to which the variance in LBM could be accounted for (Table 5). Gestation, pregnancy interval, prepregnant weight, and mother's smoking were the only measured variables which significantly accounted for variance in LBM. The amount of variance explained was less, being only $37.4 \%$; mother's smoking accounted for $6.24 \%$ and had the direct effect of reducing LBM by $204 \mathrm{~g}$; prepregnant weight and pregnancy interval together accounted for $7.5 \%$ and gestation accounted for $23.7 \%$.

\section{DISCUSSION}

The data presented herein agree with the findings of others (1, 2) that smoking during pregnancy is a significant factor affecting birth weight. Other factors also play a role; however, in the regression analysis data, smoking is the only measured variable negatively affecting birth weight. This analysis showed that smoking accounted for $7.6 \%$ of the variance in birth weight and had the direct effect of reducing birth weight by an average of $269 \mathrm{~g}$ (Table 5); the difference between this value and the observed difference in birth weight of $358 \mathrm{~g}$ between the groups reflects the indirect effects of smoking on birth weight, i.e. by affecting the other variables in the equation.

Other variables measured which potentially influence birth weight and LBM, such as weight gain in pregnancy and reported alcohol consumption, were not significant factors in this study, presumably because there were too few subjects for analysis or because only minor differences in these variables existed between the mothers. While not specifically examined in this study, socioeconomic status and amount of prenatal care received by the mothers are probably not significant factors influencing birth weight, because in Alberta, which has a system of Medicare, access to health care is universal.

Other workers (3-5) have demonstrated no effect of a mother's smoking during pregnancy on the skinfold thickness of her 
newborn infant, and Harrison et al. (3) postulated that it chiefly affects the lean tissue. Our present data are similar to those reported by the above workers in that we also could demonstrate no difference in mean skinfold thickness of the two study groups and no correlation between smoking and skinfold thickness; however, the availability of TBK data permitted us to quantify intergroup differences in body composition.

The striking effect of the mothers' smoking was on the body composition of their infants; the weight deficit was not proportional, being preferentially in lean tissue. This suggests that it is not nutrition per se that influences birth weight. It may be an adaptive response by the body to the effects of nicotine, as has been suggested by others, a conclusion that is consistent with our finding of no difference in the mothers' height, reported prepregnancy weight, or weight gain during pregnancy.

As lean tissue appears to be the most affected, the main effect appears to be impairment in protein synthesis. Hypoxia, secondary to vasoconstriction and impaired placental function, is a commonly suggested pathway for the effects of smoking on fetal growth $(1,2,9)$. Smoking reduces protein synthesis in vivo and in vitro (10) and may also lead to lipid accumulation in cells (11). Alternatively, or perhaps as well, deficiency of folic acid in the mother who smokes may be responsible. Folic acid is necessary to the synthesis of protein, and deficiency of this vitamin is common during pregnancy (12) and is more pronounced in smokers (13).

Although LBM may be directly affected by smoking, another coexisting mechanism may also act to promote lipogenesis or inhibit lipolysis. Increased activity of lipoprotein lipase, a key enzyme in the uptake and storage of fatty acids by adipocytes, has been postulated to explain the weight gain observed in some individuals after cessation of cigarette smoking $(14,15)$. The mechanism whereby smoking affects this enzyme is uncertain but the end result appears to be a adaptation whereby smokers maintain their adipose tissue mass. This might explain the maintenance of the fat mass in the infants of smoking mothers. Altered lipoprotein lipase metabolism is unlikely to be the only mechanism by which smoking affects growth, however, if it were, the end result should be only an increase in fat mass and not a decrease in birth weight and in LBM, both phenomena well documented herein.
Most likely the true mechanism is a composite of those discussed above plus others not yet recognized. However, we believe that the data presented herein provide new clues to the manner in which a mother's smoking affects the growth and well-being of her fetus.

\section{REFERENCES}

1. Cole PV, Hawkins LH, Roberts D 1972 Smoking during pregnancy and its effects on the fetus. J Obstet Gynaecol Br Commonwealth 79:782-787

2. Abel EL 1980 Smoking during pregnancy: a review of effects on growth and development of offspring. Hum Biol 52:593-625

3. Harrison GG, Branson RS, Vaucher YE 1983 Association of maternal smoking with body composition of the newborn. Am J Clin Nutr 38:757-762

4. D'Souza SW, Black P, Richards B 1981 Smoking in pregnancy: associations with skinfold thickness, maternal weight gain, and foetal size at birth. $\mathrm{Br}$ Med J 282:1661-1663

5. Whitelaw A 1979 Subcutaneous fat measurement as an indication of nutrition of the fetus and newborn. In: Visser HKA (ed.) Fifth Nutricia Symposium. Nutrition and metabolism of the fetus and infant. Martinus Nijhoff, The Hague, Holland; pp 131-143

6. Spady DW, Filipow LJ, Szymanski WA 1985 An infant whole body counte for measurement of total body potassium. Proceedings: XIV International Conference on Medical Physics and Biological Engineering and VII International Conference on Medical Physics, Espoo, Finland, Aug 11-16, 1985 J Int Fed Med Biol Eng 23 (suppl part 1):507-508

7. Spady DW, Filipow LJ, Overton TR, Szymanski WA 1986 Measurement of total body potassium in premature infants by means of a whole body counter. $\mathrm{J}$ Pediatr Gastroenterol Nutr (in press)

8. Forbes GB 1962 Methods for determining composition of the human body: with a note on the effect of diet on body composition. Pediatrics 29:477494

9. Mochizuki M, Maruo T, Masuko K, Ohtsu T 1984 Effects of smoking on fetoplacental-maternal system during pregnancy. Am J Obstet Gynecol 149:413-420

10. Preedy VR, Smith DM, Sugden PH 1985 The effects of 6 hours of hypoxia on protein synthesis in rat tissues in vivo and in vitro. Biochem $\mathrm{J} 228 \cdot 179-185$

11. Gordon GB, Barcza MA, Bush ME 1977 Lipid accumulation in hypoxic tissue culture cells. Am J Pathol 88:663-678

12. Tchernia G, Blot I, Rey A, Kaltwasser JP, Zittoun J, Papiernik E 1982 Materna folate status, birthweight and gestational age. Dev Pharmacol Ther 4(supp 1):58-65

13. Witter FR, Blake DA, Baumgardner R, Mellits ED, Neibyl JR 1982 Folate, carotene, and smoking. Am J Obstet Gynecol 144:857

4. Carney RM, Goldberg AP 1984 Weight gain after cessation of cigarette smoking: a possible role for adipose-tissue lipoprotein lipase. $\mathrm{N}$ Engl $\mathbf{J}$ Med 310:614-616

15. Brunzell JD, Goldberg AP, Schwartz RS 1980 Cigarette smoking and adipose tissue lipoprotein lipase. Int J Obesity 4:101-103 